\title{
Feasibility of intraoperative nerve monitoring (IONM) in endoscopic thyroid surgery
}

\author{
Anil D Rao ${ }^{*}$, Reyaz M Singaporewalla ${ }^{1}$ and AK Saleem Ahmed ${ }^{2}$ \\ ${ }^{1}$ Department of Surgery, Endocrine Surgical Division, Khoo Teck Puat Hospital, Singapore \\ ${ }^{2}$ Department of Surgery, Tan Tock Seng Hospital, Singapore
}

\begin{abstract}
Introduction: A major obstacle to the acceptability of scarless endoscopic thyroid surgery (SET) amongst surgeons is the perceived potential of nerve injury in the absence of seamless Intraoperative Nerve Monitoring (IONM). Whilst IONM can be easily carried out in conventional thyroidectomy with improved outcomes, most centres performing SET do not regularly attempt confirmatory visual documentation of the recurrent laryngeal nerve due to technical difficulty and many surgeons safeguard the nerve by leaving behind a rim of thyroid tissue along the suspensory ligament. Very few studies have evaluated the feasibility and technique of regular confirmatory visualization and safeguarding of the recurrent laryngeal nerves during SET.
\end{abstract}

Methods: We evaluated the role of IONM in a prospective non-randomized experimental study during the learning phase of SET. The first 25 consecutive patients undergoing Endoscopic Hemi-thyroidectomy by the Unilateral Axillary Breast approach for unilateral benign disease and nodule size < 60 mm and no previous neck/thyroid surgery underwent a feasibility evaluation. Nerve monitoring was carried out before and after visual inspection of the recurrent laryngeal nerve after creating a dissection space in the neck followed by $\mathrm{CO}_{2}$ insufflation. A dedicated long metallic conducting hook probe was used to sound the nerve through the $5 \mathrm{~mm}$ working port.

Results: No case was converted. 16 out of 25 (64\%) recurrent laryngeal nerves were successfully stimulated. Only 8 were visualized (32\%). 9 out of 25 RLN's could not be stimulated or visualized inspite of dedicated dissection attempts. 12 out of 25 (48\%) external laryngeal nerves were successfully stimulated. Only 2 could be visualized (8\%). There were no cases of permanent voice change.

Conclusion: IONM offers limited benefit in endoscopic thyroidectomy during its early learning stage.

\section{Introduction}

Gagner reported the first case of endoscopic neck surgery (subtotal para-thyroidectomy) in 1996 and Huschler described the first endoscopic thyroidectomy in 1997 [1,2]. Conventional thyroidectomy is a safe operation with extensive experience and no controversy regarding its indications and surgical technique. In experienced hands and with latest innovations of energy devices and intraoperative Nerve Monitoring (IONM), the results are excellent. Conventional thyroidectomy entails a skin crease incision in the anterior neck which causes permanent visible scarring. Shortening or eliminating the incisional scar in the neck has increasingly been a requirement in the pursuit of a better cosmetic outcome in thyroidectomy. A cervical incision with its resulting visible scar is considered by many patients as a non-desirable sequel. Attempts have been made to reduce the cosmetic impact of the cervical scar by a reduction in incision size and even development of video-assisted and totally endoscopic surgeries. This issue is of great importance in Asia, where the neck has a sensual attractiveness and where there is a higher risk of hypertrophic or keloid scars. Incisions via thoracic, axillary, or periareolar approaches are thus perceived as preferable [3,4]. In recent years, the pursuit of cosmesis has led surgeons to push the envelope even further and Scarless (in the neck) Endoscopic Thyroidectomy (SET) has found an increasing role in the realm of thyroid surgery. It has excellent cosmetic results $[5,6]$.

Evaluation of the role of IONM during the learning phase of such remote access thyroid surgical procedures and the recommendations thereof remain unanswered. The practice of routine identification of the recurrent laryngeal nerve (RLN) to reduce palsy rate has been advocated since long. This study deals with IONM for beginners with the SET in its initial learning phase. It was our hypothesis that IONM will have a very high positive visual identification rate in SET (100\%) even during its learning curve, making it a useful adjunct for safer surgery.

\section{Materials and methods}

This is a prospective nonrandomised experimental study. This study was performed at the inception of SET in our endocrine surgical division. The study was supported financially by the Alexandra Health Enabling Grant (Reference: Project Code - AHEG1604). After ethics approval by our institutional review board (IRB Reference: 2016/00416), 25 consecutive patients (F:M - 4:1) were recruited over a period of one year from Nov 2017 till Nov 2018 for Endoscopic Hemithyroidectomy via the unilateral axillary breast approach using the Intraoperative Nerve Monitoring. All operations were performed by two surgeons (ADR, RMS) who were well experienced with conventional thyroidectomy and minimally invasive surgical techniques. Eligibility

${ }^{\star}$ Correspondence to: Anil D Rao, Department of Surgery. Endocrine Surgical Division, Khoo Teck Puat Hospital, Singapore, Tel: +65 96621104; E-mail: dranilrao70@hotmail.com

Key words: endoscopic thyroidectomy, conventional thyroidectomy, unilateral benign disease

Received: June 08, 2020; Accepted: June 26, 2020; Published: June 30, 2020 
criteria included unilateral benign disease, nodule size less than $60 \mathrm{~mm}$ (cyst, follicular neoplasm, adenomatous goitre), and no previous neck surgery. Multinodular goiter and differentiated microcarcinoma with low risk were also included. Nodules larger than $60 \mathrm{~mm}$, substernal goiter, patients with previous neck surgery, malignancy and Graves Disease were excluded. All patients underwent preoperative ultrasound evaluation of the thyroid and breast. Purely cystic lesions that were symptomatic were aspirated twice prior to being offered surgery. All patients underwent surgeon performed fine needle aspiration for cytology of solid or predominantly solid nodules. Patients were intubated with an EMG endotracheal tube and IONM was carried out using the Inomed C2 NerveMonitor (inomed Medizintechnik GmbH. Im Hausgruen 29. 79312 Emmendingen, Germany; www. inimed.com). A disposable long nerve monitoring probe adapted to a hook device with the current set at $1.5 \mathrm{~mA}$ was used. In our approach (Unilateral Axillary Breast Approach), the $10 \mathrm{~mm}$ camera port was placed via the anterior axillary fold with two working $5 \mathrm{~mm}$ ports via the ipsilateral shoulder and circumareolar region. Data collected included patient demographics, indication for surgery, operating time, successful stimulation/visualisation of the RLN and ELN, final histology, voice change and other complications.

\section{Technique}

In this study during the use of the IONM, the protocol followed was to use IONM first to stimulate followed by dissection to visualise. Direct first dissection to identify was not used in any case. Dissection alone was used when IONM failed in spite of multiple attempts or localisation was not aided after initial positive stimulation signals. Under anaesthesia, the patient is placed in the supine position with neck extension and both arms out with head turned to the opposite side (Figure 1). Via a $10 \mathrm{~mm}$ skin incision in the anterior axillary line, the $10 \mathrm{~mm}$ camera port is inserted after initial blunt trocar insertion in the subcutaneous suprapectoral plane. After space creation, the other two $5 \mathrm{~mm}$ ports are inserted via skin incisions in the ipsilateral shoulder and circumareolar region of the ipsilateral breast (Figure 2). We proceed by raising flaps of dissection in the subcutaneous suprapectoral plane in the layer just above the fascia covering the pectoralis major. The flaps are raised by a combination of diathermy and harmonic energy device dissection under vision of the endoscope. The dissection proceeds superomedially to identify the first landmark which is the sternal notch. The limit of medial dissection is the opposite sternocleidomastoid after identifying

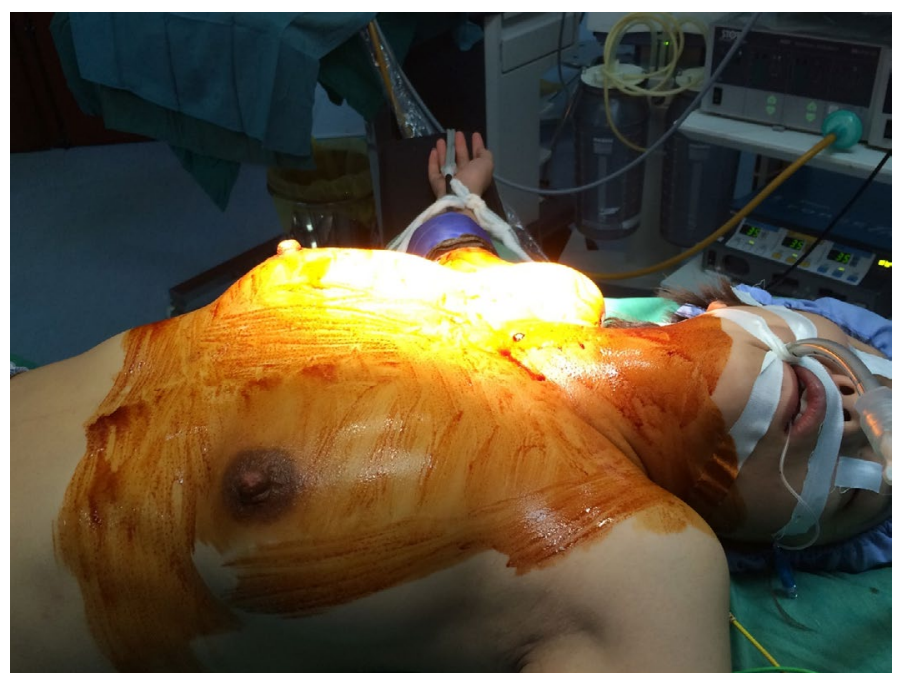

Figure 1. Patient position

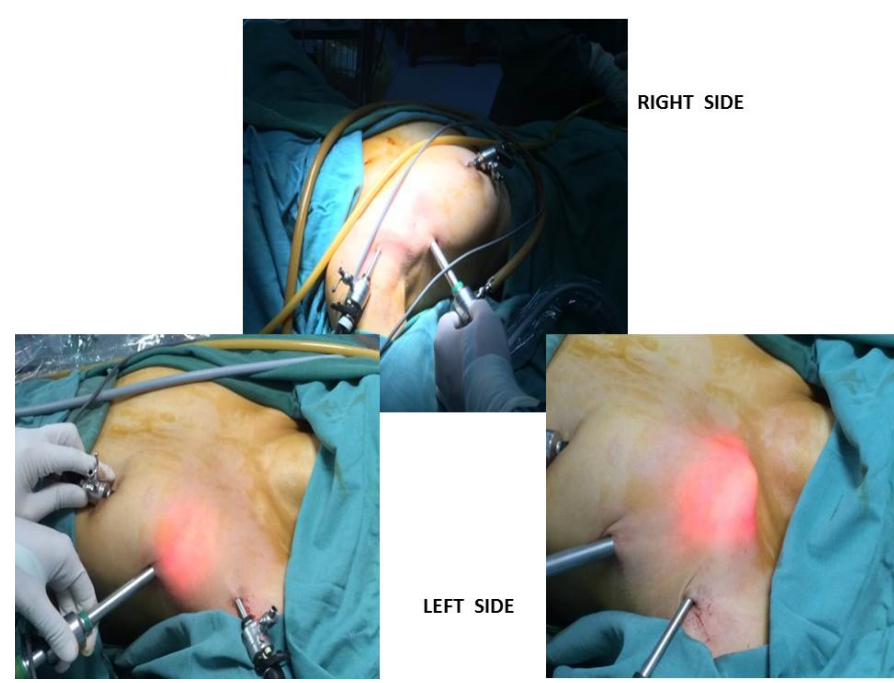

Figure 2. Port positions

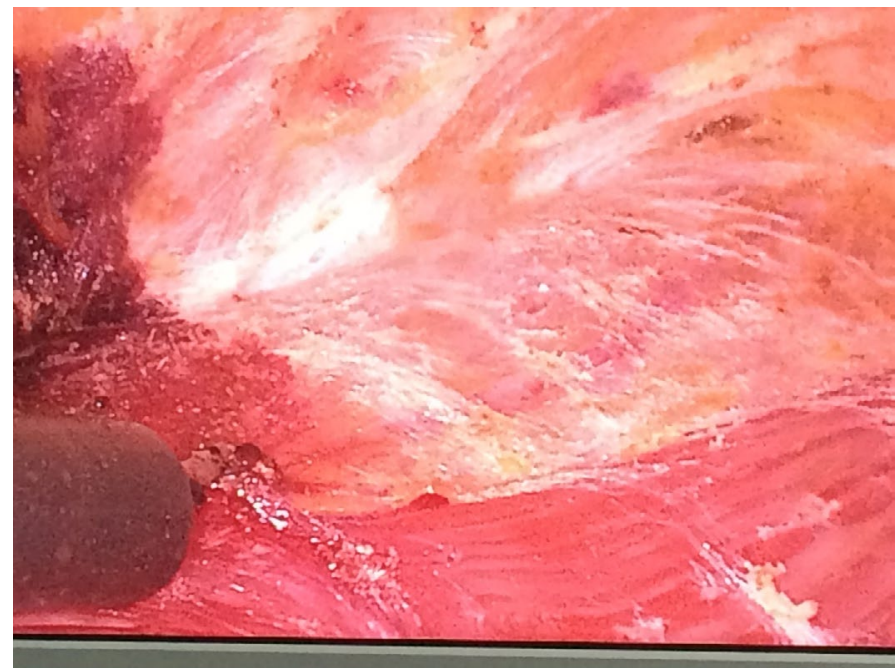

Figure 3. Set dissection landmarks

the tendon of insertion of the ipsilateral sternocleidomastoid. The superior dissection is carried out till the superior border of the thyroid cartilage and laterally till close to the lateral margin of the ipsilateral sternomastoid muscle (Figure 3). After creating an adequate neck space, the medial border of the sternomastoid is dissected sharply with diathermy followed by dissecting the inferior border of the omohyoid muscle akin to the lateral "backdoor" approach described for conventional surgery [7]. The omohyoid muscle is divided if the gland size needs additional exposure. The strap muscles are divided laterally, and the dissection thus proceeds to separate the strap muscles from the surface of the thyroid gland and approach the superior pole. Similarly, the lower pole is exposed, and the parathyroid glands are identified, most of the dissection at this point being with the harmonic energy device. The dissection is carried out as close as possible to the surface of the thyroid gland. No cord-like structure is divided unless the RLN is definitely excluded. When the inferior pole of the thyroid gland is freed, the thyroid gland is retracted medially using an endoscopic long peanut to dissect the avascular lateral plane. A plane is developed between the thyroid and the peripheral tissues adherent to the gland and middle thyroid vein if present is clipped. The focus of dissection is now the trachea-oesophageal groove and the IONM probe is used to stimulate/sound the RLN. The inferior thyroid artery is separated 
using Maryland forceps dissection. Haemostasis from bleeding due to small accompanying vessels is secured meticulously aided by compression avoiding blind usage of energy device. The RLN is usually easily identified at this stage using a combination of IONM stimulation followed by dissection as a bright cord separate from blood vessels. The branch of the inferior thyroid artery adhering to the gland is dissected close to the gland, and the inferior pole is totally freed. This is followed by dissection of the isthmus and its division to expose the trachea. The gland is then retracted downward and the Berry's ligament and upper pole of the thyroid gland including the corresponding blood vessels are dissected. With a combination of the above movements it is expected to identify the RLN to the point where it enters the larynx near the inferior horn of thyroid cartilage. The cervical RLN is thus exposed completely (Figure 4). The dissection of the upper pole facilitates the localisation of the external laryngeal nerve (ELN) using a combination of dissection and stimulation to keep the dissection plane as close to the gland as possible. For practical cases, the upper limit of dissection leaves behind a small rim of thyroid parenchyma at the upper pole to ensure safety.

\section{Results}

Between November 2017 to November 2018, 25 patients (F20, M-5) underwent endoscopic hemi-thyroidectomy. Patient demographics, nodule size and histology are presented in table 1 . The other operative details are shown in table 2 . There were no conversions or major complications. The mean operating time was 137 minutes. 16 out of 25 (64\%) RLN's were accurately electrically stimulated. Only 8 RLN's were visualised positively (32\% overall). 4 out of 8 RLN's that were visualised positively had their focussed dissection directly aid positive visual identification thereby having their success attributable to IONM, whereas the other 4 RLN's after initial stimulation using the IONM could not be visualised by directed dissection attempts and were subsequently visualised by dissection unaided by IONM. 12 out of 25 (48\%) ELN's were accurately electrically stimulated. Only 2 ELN's could be positively identified ( $8 \%$ overall).

The nerve visualisation rate (RLN and ELN) was better from case 16 to case 25 as against case 1 to case 15 (RLN: 6 vs 2/ELN: 2 vs $0 . n s$ )

Port insertion and flap raising times assessed as a cumulative sum showed a statistically significant progressive improvement in the second part of the series (case 16 to 25$),(\boldsymbol{p}<\boldsymbol{0 . 0 1})$. Mean length of stay was 2.2 days (range 2-3). One patient experienced transient hoarseness of voice which recovered fully on post-operative day (POD) 10. Vocal cord evaluation was normal at follow up examination. Other minor complications like neck paraesthesia-2, seroma-2 and protracted neck paraesthesia-1 recovered fully. Pain scores at recovery, 6 hours and on 1st POD were 2, 1.8 and 2.3 (range $1-5,1-3$ and $1-4$ respectively). Average pain score at clinic follow-up was $1.6(0-4)$ with complete
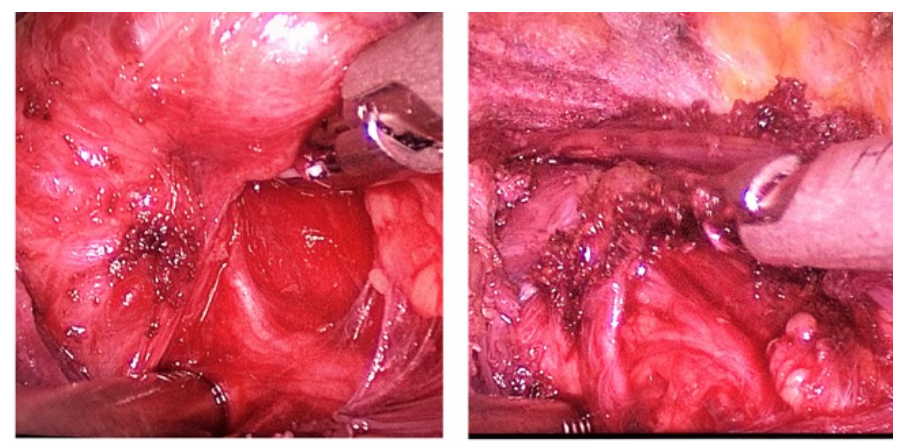

Figure 4. Recurrent laryngeal nerve exposed
Table 1. Demographics

\begin{tabular}{|l|c|}
\hline Demographics & \\
\hline Age in years (range) & $41.5(17-59)$ \\
\hline Sex ratio (Female: Male) & $4: 1$ \\
\hline NODULE SIZE, cm (range) & $3.2(1.8-6)$ \\
\hline DIAGNOSIS & $\mathrm{n}(\%)$ \\
\hline Purely Cystic & $3(12)$ \\
\hline Complex Cyst & $4(16)$ \\
\hline STN & $9(36)$ \\
\hline Dominant Nodule & $9(36)$ \\
\hline Final Histology & $\mathrm{n}(\%)$ \\
\hline Multi-nodular colloid goiter & $9(36)$ \\
\hline Solitary hyperplastic/adenomatous nodule & $8(32)$ \\
\hline Degenerating cyst & $8(32)$ \\
\hline
\end{tabular}

Table 2. Operative details. $P<0.01$. RLN: Recurrent Laryngeal Nerve; ELN: External Laryngeal Nerve; IONM: Intraoperative Nerve Monitoring

\begin{tabular}{|c|c|c|c|}
\hline \multicolumn{2}{|c|}{ Blood Loss, ml (range) } & \multicolumn{2}{|l|}{$40(25-75)$} \\
\hline \multirow{2}{*}{\multicolumn{2}{|c|}{ RLN - IONM Stimulated, n (\%) }} & \multirow[b]{2}{*}{$16(64 \%)$} & Subsequent visual confirmation - $4(16 \%)$ \\
\hline & & & $\begin{array}{l}\text { Only stimulated with no subsequent } \\
\text { visual confirmation achieved - } 12(48 \%)\end{array}$ \\
\hline \multirow{2}{*}{\multicolumn{2}{|c|}{ VisuaL RLN Identification, n (\%) }} & \multirow{2}{*}{$8(32 \%)$} & Aided by IONM - $4(16 \%)$ \\
\hline & & & Aided by dissection alone $-4(16 \%)$ \\
\hline \multirow{2}{*}{\multicolumn{2}{|c|}{ ELN - IONM Stimulated, n (\%) }} & \multirow[b]{2}{*}{$12(48 \%)$} & Subsequent visual confirmation $-2(8 \%)$ \\
\hline & & & $\begin{array}{l}\text { Only stimulated with no subsequent } \\
\text { visual confirmation }-10(40 \%)\end{array}$ \\
\hline \multirow{2}{*}{\multicolumn{2}{|c|}{ Visual ELN Identification, n (\%) }} & \multirow{2}{*}{$2(8 \%)$} & Aided by IONM - $2(8 \%)$ \\
\hline & & & Aided by dissection alone - 0 \\
\hline \multicolumn{2}{|c|}{$\begin{array}{l}\text { Operative Duration, minutes } \\
\text { (range) }\end{array}$} & \multicolumn{2}{|r|}{ Nerve Identification } \\
\hline $\begin{array}{l}\text { Total operative } \\
\text { duration }\end{array}$ & $137(99-180)$ & RLN & ELN \\
\hline $\begin{array}{l}\text { Port insertion for } 1^{\text {st }} \\
\text { fifteen cases }\end{array}$ & $19(15-20)$ & \multirow{2}{*}{$\begin{array}{l}\text { Case } 1 \text { to } \\
15-2\end{array}$} & \multirow{2}{*}{ Case 1 to $15-0$} \\
\hline $\begin{array}{l}\text { Flap raising for } 1^{\text {st }} \\
\text { fifteen cases }\end{array}$ & $52(44-65)$ & & \\
\hline $\begin{array}{l}\text { Port insertion for } \\
\text { last } 10 \text { cases }\end{array}$ & $13(10-19)$ & \multirow{2}{*}{$\begin{array}{l}\text { Case } 16 \text { to } \\
25-6\end{array}$} & \multirow{2}{*}{ Case 16 to $25-2$} \\
\hline $\begin{array}{l}\text { Flap raising for last } \\
10 \text { cases }\end{array}$ & $33(25-38)$ & & \\
\hline
\end{tabular}

resolution of any residual chest wall paraesthesia and numbness. Mean duration of follow-up was 6.3 months (3-11). 20 out of 25 graded their experience as excellent with 4 grading it as good and 1 as unsatisfactory. The patient who graded it as unsatisfactory experienced protracted paraesthesia and some degree of sharp pain on neck movement, which however completely resolved on long term follow-up.

\section{Discussion}

SET and its various modifications have been known since about 20 years. Remote access procedures like SET are longer and more expensive than conventional procedures. A scar and change in voice are unacceptable to many patients. One of the main perceived drawbacks of the SET and these newer remote access techniques of thyroidectomy is the difficulty of locating and preserving the recurrent laryngeal nerve (RLN). Nerve injury is a severe complication of thyroid surgery. It leads to permanent hoarseness, difficulty in swallowing and respiratory problems and is one of the leading causes of medicolegal litigation due to the attendant reduction in quality of life [8-10]. IONM is not far from being accepted as standard of care in conventional thyroidectomy and as such it remains essentially unevaluated in minimally invasive procedures since endoscopic thyroid surgery is still in its infancy as far as universal acceptability is concerned. Routine identification of the 
RLN and the belief that this leads to significantly reduced palsy rate has been advocated since the 1930's [11-13]. IONM has reduced risks of nerve injury in conventional thyroidectomy and is feasible for allcomers regardless of degree of experience [14,15]. Some randomized studies have shown reduction in risk of temporary nerve injury with specific benefit in nerve visualization which is probably of paramount importance if extrapolated to remote access surgeries [16,17]. It has been reported that routine nerve dissection and visualization of the RLN during thyroidectomy can preserve the integrity of the nerve and routine visual identification of the RLN is currently included in guidelines as standard of care by some experts $[18,19]$.

Minimal access techniques require skilled surgeons and have a long learning curve, and may have an increased morbidity, with a higher proportion of classical complications, such as hoarseness, haemorrhage, or hypocalcaemia, and the occurrence of other complications, rare in open cases, such as seromas, wound infections, or subcutaneous emphysema [20-22]. Research on learning curves and feasibility are needed to bolster clinical experience. The aim of this study was to evaluate the feasibility of Intraoperative Nerve Monitoring (IONM) during the performance of endoscopic thyroidectomy. It is likely that the desire for cosmesis will push the indications for SET and the safety standards of this procedure obviously need to keep up with its conventional counterpart. The usual risks of nerve injury are possibly intuitively higher with SET and the risks are expectedly even higher during its learning phase. This study deals with the evaluation of IONM for beginners with SET in its initial learning phase. We postulated that IONM will have a high positive identification rate in SET even during its learning curve making it a useful adjunct for safer surgery. Some literature reports suggest that the first 60 cases constitute the learning curve for SET. Evaluation of the role of IONM in this crucial phase and the recommendations thereof remain unanswered. Even experienced surgeons have reported inadvertent injury to nerves and persistent palsy in $1-2 \%$ of cases [23-25].

RLN injury is supposed to be lower in patients who had IONM rather than dissection visualization alone. Many experts believe that exposing the RLN is essential to protect it and that this holds true for endoscopic surgery also. If this is to be followed, optimal dissection methods need to be employed with a high level of confidence regarding visual identification with all aids possible since dissection during remote access techniques is expectedly different and needs a skill set different from that of conventional thyroidectomy. The authors believe that any experienced thyroid surgeon who is new to SET procedures will face the dilemma of the optimum technique of dealing with the recurrent laryngeal nerve. The techniques of exposure of the RLN in endoscopic thyroid surgery have been described by Chang et al. [26]. The following steps have been emphasized

\section{- Mobilisation of isthmus first}

- Reduction of thermal injury to the RLN by staying close to the thyroid capsule

- Identifying the RLN inferiorly in the TE groove aided by the IONM.

IONM is also known to reduce the dissection time of RLN [27]. The authors in their initial pilot experience and personalised communication with other experienced thyroid surgeons have encountered the option of avoiding visualization of the nerves. This can be achieved during the key steps of the SET by leaving behind a rim of thyroid tissue along the suspensory ligament. Whether this is desirable or safe is a matter of discussion that possibly concerns every thyroid surgeon when he first ventures into SET. With an extensive experience in the use of IONM and its intricacies in conventional thyroidectomy, the authors believe that this is an oversimplification as far as the initial learning period of SET is concerned as firstly, the risks of complications are higher and secondly, the dissection skill set of conventional thyroidectomy can not be extrapolated to SET. The different visual angles and manipulation methods during the performance of the SET make dissection and visualization of the nerves technically unique. The fear of nerve injury early in the learning curve, we believe reduces the applicability and the use of the IONM. Most surgeons will use the IONM but the first few cases will typically see most surgeons leave behind a rim of thyroid tissue along the suspensory ligament to safeguard the nerve. It can also be argued that a misplaced zeal to visually identify the RLN especially during the early phase in any surgeons learning curve can lead to inadvertent injury with catastrophic consequences [28].

The literature has limited publications on feasibility and IONM outcomes during SET. The authors at the outset clarified that for the purpose of the study during the use of the IONM, the protocol followed was to use IONM first to stimulate followed by dissection to visualise. Direct first dissection aimed at visual identification was not used in any case. It can be argued that when faced with a new remote access procedure with seemingly new dissection techniques, the risk of nerve injury due to attempt to visualise itself remains unevaluated. Dissection alone was used when IONM failed inspite of multiple attempts. The overall RLN identification rate in our study was 8 out of $25(32 \%)$. This is a far cry from the initial presupposed hypothesis of $100 \%$ based on the surgeons extrapolated conventional experience. Additionally, only 4 out of these 8 were aided by IONM whilst the other 4 relied on dissection alone. This further raises questions about the utility of IONM during this phase. It can be argued that the positive stimulation rate of our study was $16 / 25$ (64\%) which is reasonably high. Some would argue that positive stimulation is a step better than blind dissection as it aids injury prevention. The ELN identification remains very difficult in the experience of the authors as noted by a low overall rate of $2 / 25(8 \%)$. It is curious to note that in our series the identification rates improved during cases 16-25. This difference albeit not statistically significant lends credence to the other finding in our series of that of port insertion and flap raising times assessed as a cumulative sum which showed a statistically significant progressive improvement during the same time frame. This has logical implications of ease of performance with increasing numbers and increased confidence at dissection attempts. One of the perceived difficulties of adopting the IONM in remote access techniques is the long distance between the skin incision/port and the operative field. There are claims of improved sense of safety while using the IONM. However, these claims are negated by markedly different approaches to nerve dissection with the advent of the IONM. Some surgeons make a case for no change in technique with continued visualization and dissection of the RLN in the same manner as prior to the advent of the IONM, whilst some surgeons have reported a gradual move towards less invasive dissection by checking the RLN location using the IONM without systematic visualization and restricted dissection close to the thyroid capsule. This suggestion, however, emanates from the initial experience with conventional thyroidectomy [29]. The authors inclination is towards the safety and promise of the second approach and advocate it during the initial learning phase of the SET. This also will serve as a fallback option of surgical safety during the performance of the SET for allcomers. The basis for this is the assumption and understanding that literature reports show a possible requirement of up to 100 cases to master IONM. This makes a weak case for the intuitive recommendation of perceived safety of the IONM 
during the initial learning curve of SET. A commonsense approach is that overtly invasive dissection could be held responsible for RLN palsies when either a procedure is new for the surgeon or the surgeon is new to the procedure $[30,31]$.

\section{Conclusions}

The aim of this paper was to test the feasibility of IONM as a skill transferred from conventional open thyroidectomy to SET during the initial few cases. This paper is unique in that it deals with the travails and trepidations of the fear of a potentially catastrophic morbidity during the performance of a new procedure with an old established technology. The earlier the nerve is identified, the lower is the surgeon's level of stress. This is true with conventional as well as remote access techniques. The sheer fear of a new procedure with a potentially catastrophic complication can make any newcomer to play safe by utilising a safe perithyroidal dissection thus negating the possible role of the IONM. This is possible till the surgeon becomes comfortable with the procedure. The authors in their experience with conventional cases, either confirm the path of the nerve after visualization or use IONM to aid location when identification is difficult. The optimum technique and approach in SET remains a matter of debate. IONM directed stimulation of the RLN for beginners in endoscopic surgery can be high $(64 \%)$. However only up to a third of RLN's can be expected to be positively visualised during the early learning phase of the SET even for surgeons with extensive experience in conventional surgery. The ELN stimulation and visual identification rates are low. The attempts at dedicated visualisation to safeguard nerves can not be extrapolated from conventional to SET particularly during its learning phase as seen by our low exposure rate of $8 \%$ ( 4 out of 25 cases). At this point of time IONM, unlike conventional surgery, does not appear to be fully feasible during SET. The option of using the IONM to sound nerves followed by avoiding visualization of the nerves during the key steps of the SET by leaving behind a rim of thyroid tissue along the suspensory ligament may be desirable and safe till experience improves.

\section{Acknowledgements}

Funding Information: Alexandra Health Enabling Grant; Reference: Project Code - AHEG1604; IRB Reference: 2016/00416; Funding Agency: Alexandra Health Fund Limited.

\section{Reference}

1. Gagner M (1996) Endoscopic subtotal parathyroidectomy in patients with primary hyperparathyroidism. Br J Surg 83: 875. [Crossref]

2. Huschler CS, Chiodini S, Napolitano C, Recher A (1997) Endoscopic right thyroid lobectomy. Surg Endosc 11: 877. [Crossref]

3. Linos D (2011) Minimally invasive thyroidectomy: A comprehensive appraisal of existing techniques. Surgery 150: 17-24. [Crossref]

4. Duh QY (2011) Robot-assisted endoscopic thyroidectomy: Has the time come to abandon neck incisions? Ann Surg 253: 1067-1068. [Crossref]

5. Wang M, Zhang T, Mao Z, Dong F, Li J, et al. (2009) Effect of endoscopic thyroidectomy via anterior chest wall approach on treatment of benign thyroid tumors. J Laparoendosc Adv Surg Tech A 19:149-152. [Crossref]

6. Tan CT, Cheah WK, Delbridge L (2008) Scarless (in the neck) endoscopic thyroidectomy (SET): an evidence-based review of published techniques. World J Surg 32: 1349-1357. [Crossref]

7. Singaporewalla RM, Tan BC, Rao AD (2017) The lateral "backdoor" approach to open thyroid surgery: A comparative study. Asian J Surg 41: 384-388. [Crossref]

8. Shaw GY, Pierce E (2009) Malpractice Litigation Involving Iatrogenic Surgical Vocal Fold Paralysis: A Closed-Claims Review with Recommendations for Prevention and Management. Ann Otol Rhinol Laryngol 118: 6-12. [Crossref]

9. Ta JH, Liu YF, Krishna P (2016) Medicolegal Aspects of Iatrogenic Dysphonia and Recurrent Laryngeal Nerve Injury. Otolaryngol Head Neck Surg 154: 80-86. [Crossref]
10. Acun Z, Cinar F, Cihan A, Ulukent SC, Uzun L, et al. (2005) Importance of identifying the course of the recurrent laryngeal nerve in total and near-total thyroid lobectomies. Am Surg 71: 225-227. [Crossref]

11. Lahey FH, Hoover WB (1938) Injuries to the recurrent laryngeal nerve in thyroid operations: their management and avoidance. Ann Surg 108: 545-562. [Crossref]

12. Jatzko GR, Lisborg PH, Muller MG, Wette VM (1994) Recurrent nerve palsy after thyroid operations - principal nerve identification and a literature review. Surgery 115: 139-144. [Crossref]

13. Hermann M, Alk G, Roka R, Glaser K, Freissmuth M (2002) Laryngeal recurrent nerve injury in surgery for benign thyroid diseases: effect of nerve dissection and impact of individual surgeon in more than 27000 nerves at risk. Ann Surg 235: 261-268. [Crossref]

14. Bergenfelz A, Salem AF, Jacobsson H, Nordenstrom E, Almquist M (2016) Risk of Recurrent Laryngeal Nerve Palsy in Patients Undergoing Thyroidectomy with and Without Intraoperative Nerve Monitoring. Br J Surg 103: 1828-1838. [Crossref]

15. Dralle H, Sekulla C, Lorenz K, Brauckhoff M, Machens A (2008) Intraoperative Monitoring of the Recurrent Laryngeal Nerve in Thyroid Surgery. World J Surg 32 1358-1366. [Crossref]

16. Lee J, Nah KY, Kim RM, Ahn YH, Soh EY, et al. (2010) Differences in postoperative outocmes, function and cosmesis: open vs robotic thyroidectomy. Surg Endsoc 24: 3186-3194. [Crossref]

17. Barczynski M, Konturek A, Cichon S (2009) Randomized clinical trial of visualization versus neuromonitoring of recurrent laryngeal nerve during thyroidectomy. Br J Surg 96: 240-246. [Crossref]

18. White WM, Randolph GW, Hartnick CJ, Cunningham MJ (2009) Recurrent laryngeal nerve monitoring during thyroidectomy and related cervical procedures in the pediatric population. Arch Otolaryngol Head Neck Surg 135: 88-94. [Crossref]

19. Chan WF, Lang BH, Lo CY (2006) The role of intraoperative neuromonitoring of recurrent laryngeal nerve during thyroidectomy: A comparative study on 1000 nerves at risk. Surgery 140: 866-872; discussion 872-863. [Crossref]

20. Chen GZ, Zhang X, Shi WL, Zhuang ZR, Chen X, et al. (2012) Systematic comparison of cervical and extracervical surgical approaches for endoscopic thyroidectomy. Surg Today 42: 835-841. [Crossref]

21. Choi JY, Lee KE, Chung KW, Kim SW, Choe JH, et al. (2012) Endoscopic thyroidectomy via bilateral axillo-breast approach (BABA): Review of 512 cases in a single institute. Surg Endosc 26: 948-955. [Crossref]

22. Chen B, Wang Y, Xuan S, Zhang G, Hu S, et al. (2012) Endoscopic thyroidectomy: The development in a Chinese center. J Laparoendosc Adv Surg Tech A 22: 76-80. [Crossref]

23. Bergamschi R, Becouarn G, Ronceray J, Arnaud JP (1998) Morbidity of thyroid surgery. Am J Surg 176: 71-75. [Crossref]

24. Fewins J, Simpson CB, Miller FR (2003) Complications of thyroid and parathyroid surgery. Otolaryngol Clin North Am 36: 189-206. [Crossref]

25. Erbil Y, Barbaros U, Issever H, Borucu I, Salmaslioğlu A, et al. (2007) Predictive factors for recurrent laryngeal nerve palsy and hypoparathyroidism after thyroid surgery. Clin Otolaryngol 32: 32-37. [Crossref]

26. Chang S, Tang HH, Wang CC, et al. (2012) A standard approach to expose the recurrent laryngeal nerve during endoscopic thyroidectomy. $J$ Laparoendosc Adv Surg Tech A 22: 259-263. [Crossref]

27. Sari S, Erbil Y, Sumer A, Agcaoglu O, Bayraktar A, et al. (2010) Evaluation of recurren laryngeal nerve monitoring in thyroid surgery. Int J Surg 8: 474-478. [Crossref]

28. Chan WF, Lang HH, Lo CY (2006) The role of intraoperative nerve monitoring of recurrent laryngeal nerve during thyroidectomy. A comparative study on 1000 nerves at risk. Surgery 140: 866-872. Discussion 872-863. [Crossref]

29. Duclos A, Lifante JC, Ducarroz S, Soardo P, Colin C, et al. (2011) Influence of the intraoperative neuromonitoring on surgeons technique during thyroidectomy. World $J$ Surg 35: 773-778. [Crossref]

30. Dionigi G, Bacuzzi A, Boni L, Rovera F, Dionigi R, et al. (2008) What is the learning curve for intraoperative neuromonitoring in thyroid surgery? Int J Surg 6: S7-S12. [Crossref]

31. Jonas J, Bahr R (2006) Intraoperative neuromonitoring of the recurrent laryngeal nerve - results and learning curve. Zentralbl Chir 131: 443-448. [Crossref]

Copyright: (C2020 Rao AD. This is an open-access article distributed under the terms of the Creative Commons Attribution License, which permits unrestricted use, distribution, and reproduction in any medium, provided the original author and source are credited. 